\title{
O SABER KAMAIURÁ SOBRE A SAÚDE DO CORPO
}

\author{
Carmen Junqueira* \\ Heloisa Pagliaro ${ }^{* *}$
}

\begin{abstract}
Os Kamaiurá são um povo de língua Tupi que, juntamente com povos das famílias linguísticas Aruak, Karib, Tupi e da língua isolada Trumai, habita o Alto Xingu (MT). A homogeneidade cultural entre esses povos é evidenciada em múltiplos aspectos, como forma e disposição das aldeias, tipo de habitação, hábitos alimentares, reclusão pubertária, pinturas e adornos corporais, uso do uluri pelas mulheres, festas e cerimônias, como o Kwaryp. Esse padrão cultural comum resulta da longa ocupação de uma mesma área geográfica e da frequência de casamentos interétnicos. O presente trabalho mostra como o saber sobre a saúde do corpo é construído a partir de elementos que compõem a visão do mundo Kamaiurá, em que observação, experimentação e mitologia se conjugam. Descreve os cuidados dispensados ao corpo e as regras culturais e espirituais relativos às diferentes etapas do ciclo vital.
\end{abstract}

PALAVRAS-CHAVE: Kamaiurá, saúde indígena, saúde reprodutiva de povos indígenas.

Os Kamaiurá são um povo de língua Tupi que, juntamente com outros nove povos das famílias linguísticas Aruak, Karib, Tupi e da língua isolada Trumai, habita a região dos formadores do rio Xingu, ao norte do estado do Mato Grosso (Brasil Central). A grande homogeneidade cultural entre esses povos é evidenciada em múltiplos aspectos, como forma e disposição das aldeias, tipo de habitação, hábitos alimentares, reclusão pubertária, pinturas e adornos corporais, uso do uluri pelas mulheres, festas e cerimônias, como o Kwaryp. Esse padrão cultural comum teria resultado da longa ocupação de uma mesma área geográfica e da frequência de casamentos interétnicos.

Os Kamaiurá têm uma preocupação constante com a saúde e desenvolveram uma série de procedimentos voltados para a prevenção e a cura de doenças. São muitas as práticas adotadas, e as mais usadas são o vomitório, a sangria realizada

* Doutora em Antropologia. Professora titular e emérita do Departamento de Antropologia da Faculdade de Ciências Sociais da Pontifícia Universidade Católica de São Paulo. Rua Monte Alegre, 984 - Perdizes. Cep: 05014-001 - Sao Paulo, SP - Brasil. carmen.junqueira@terra.com.br

* * Cientista social. Doutora em Saúde Pública pela Universidade de São Paulo. pagliaro@unifesp.br por meio da escarificação, a ingestão de remédios em forma de chá ou infusão de ervas, defumações, resguardo e recolhimento associados à dieta alimentar em determinados períodos da vida. As ações preventivas iniciam-se na infância e prosseguem por toda a vida e, se bem observadas, garantirão uma existência tranquila até a velhice. São práticas transmitidas através das gerações, consagradas pela tradição e que se apoiam nas qualidades curativas de plantas, em revelações e interpretações xamânicas e no conhecimento registrado nas narrativas orais. Para entender o complexo conjunto de concepções que as envolve, é preciso seguir até o universo imaginário que lhes dá fundamento, em que são muitos os fenômenos que se cruzam, sendo difícil estabelecer domínios separados, limites claramente demarcados para manifestações da prática social, de conhecimentos técnicos, de saberes espirituais e de procedimentos mágicos. De um modo ou de outro, todos concorrem para explicar, justificar ou legitimar regras do convívio social, desempenhos rituais e intervenções práticas.

O objetivo deste texto é mostrar como o saber sobre a saúde é construído a partir de elemen- 
tos que compõem a visão de mundo kamaiurá, em que observação, experimentação e mitologia se conjugam. Assim, por exemplo, conhecimentos sobre a eficácia de plantas na cura de doenças, aquilo que C. Lévi-Strauss denominou de ciência do concreto, coexistem ao lado de terapias xamânicas e de narrativas orais que registram a cosmogonia tradicional e também paradigmas comportamentais. Todos eles podem ser evocados para conduzir uma cura ou definir os cuidados com a saúde. Essas três fontes de saber são integradas: várias plantas foram dotadas do poder de cura por agentes mitológicos; os espíritos observam o comportamento humano, punem transgressões e podem ajudar a curar; a observação é um exercício cotidiano na aldeia, que comanda a maior parte dos modos de aprender. E, finalmente, a experimentação é uma clara explicitação da curiosidade intelectual kamaiurá, que se traduz no desejo de conhecer.

O modo de pensar kamaiurá é claramente racional se conhecermos os fundamentos que o sustentam. Maturana enfatiza com bastante propriedade que "todo argumento sem erro lógico é obviamente racional para aquele que aceita as premissas fundamentais em que ele se baseia” (2005, p.18). E quais seriam as premissas básicas do pensamento kamaiurá? Pensamos ter detectado algumas delas: 1) a vida deve se prolongar do nascimento à velhice. Para que isso se concretize, é preciso atenção às regras alimentares e aos rituais, legados pelas gerações passadas; 2) são necessários cuidados básicos com o corpo, desde a vida intrauterina, pois, da concepção até os 3 ou 4 anos de idade, a saúde do indivíduo é diretamente afetada pelo tipo de alimentação que recebe e pela alimentação de seus pais; 3) a doença é sempre fruto de uma ação externa ao corpo, sendo importante não descuidar das práticas preventivas; 4) a morte tem apenas duas origens: feitiço e, em casos pontuais, atuação de espíritos.

Quando iniciamos o estudo sobre os fatores culturais que teriam possibilidade de afetar direta ou indiretamente os cuidados com a saúde, focalizamos regras, prescrições e tabus que ordenavam a conduta costumeira e que eram, de certa forma, bastante evidentes, como, por exemplo: a expectativa generalizada de que todas as pessoas devem se casar e constituir família; o casamento das mulheres logo após a primeira menstruação; o período de luto e abstinência sexual que se segue à morte do cônjuge; restrições sexuais impostas ao pajé tanto durante sua iniciação como por ocasião de rituais de cura; o uso de ervas capazes de evitar a concepção ou interrompê-la; os diversos cuidados que cercam a gravidez, a reclusão pubertária, os nascimentos e a doença. Estávamos cientes de que informações relevantes e inesperadas poderiam começar a aparecer depois de períodos prolongados de pesquisa, quando o observador passa a ter uma visão mais completa daquilo que EvansPritchard (1978) sugeriu ser a apreensão da gramática mental do povo, isto é, o acesso a ideias-chave do raciocínio do povo estudado. Para apreendê-las, é necessário dirigir a atenção aos múltiplos aspectos que cercam os acontecimentos da vida na aldeia, para, aos poucos, compor o mosaico organizado segundo uma lógica a ser também desvendada. Cada informaçãoé uma nova peça colocada na construção do compreender que subjaz a organização das ideias e do pensar. Nesse processo, não se pode trabalhar com definições prematuras, mas seguir pacientemente os, às vezes, intrincados processos mentais elaborados pelos intelectuais nativos.

Com isso em mente, retornamos aos principais estudos publicados sobre os Kamaiurá ${ }^{1}$ e, na impossibilidade de passar um único período prolongado com eles, realizamos seis viagens à aldeia de Ipavu (agosto e setembro de 2003, agosto de 2004, julho de 2005, 2006 e 2007), quando coletamos dados necessários à análise das questões centrais do nosso estudo, aqui apresentadas. Fizemos uso da observação participante, com foco dirigido principalmente às questões relativas à saúde, realizamos entrevistas com pajés e especialistas em ervas curativas, agentes de saúde e outros membros da comunidade entre homens e mulheres mais velhos. Coletamos mitos e outras narrativas sobre a constituição do universo imaginário.

${ }^{1}$ Galvão (1979), Oberg (1953), Agostinho (1974), Villas Boas (2000) e Samain (1980). 
Percebemos, em pouco tempo, que a realidade vivida pelos kamaiurá era mais ampla do que a simples percepção da aldeia, das roças, matas e águas e se estendia a dimensões que iam além do visível. Cada espaço do cenário guardava uma história atrás de si que revelava a origem, o sentido das coisas e também nomeava os seres que compartilhavam a existência com os humanos. No universo primordial, diziam os narradores, viviam as aves, os peixes, os animais da mata, os espíritos e um único ser, com a forma de homem, chamado Mavutsinin. Os espíritos (mama’e) eram em grande número, pairavam sobre todos os recantos.

A noção de espírito não é de fácil apreensão e se aproxima da ideia de potência, de força que atua no mundo visível e provoca acontecimentos. É um ser que atua no âmbito do seu domínio, que tanto pode ser uma espécie animal, vegetal ou objeto cerimonial, sendo referido como seu dono ou protetor. Caso se peça ao Kamaiurá que faça uma representação gráfica do espírito, ela será conforme $o$ aspecto físico do animal, do vegetal ou objeto a que esteja vinculado: uma espécie de peixe, de planta, de máscara ou outro artefato. Nas narrativas mitológicas, os espíritos aparecem tanto com essa imagem como na forma humana. Esclarecer tal ambivalência não faz parte da preocupação dos pensadores kamaiurá, mas apenas reafirmar o poder de que são possuidores.

Esclarecida a questão da aparência dos espíritos, é possível compreender melhor os acontecimentos que ocorreram no começo dos tempos, no que é hoje a região de Morená, na confluência dos rios Ronuro, Batovi e Culuene, morada desses seres primordiais que, assim como Mavutsinin, existiram desde sempre, sem nunca terem sido criados. Foi nesse local que certo dia Mavutsinin viu uma concha na beira da água e com ela se casou. Da união nasceu uma criança, tendo Mavutsinin perguntado: é homem ou mulher? É homem, respondeu a concha. Então levo comigo. A concha, chorando, fechou-se e voltou para as águas. O novo ser gerado pelos dois recebeu o mesmo nome do pai. Mas, como na tradição kamaiurá é o nome do avô que deve ser passado ao neto, os narradores advertem: "Ele era filho de Mavutsinin, mas nós dizemos que era neto".

Mavutsinin neto é o criador da humanidade, obra também realizada em Morená. "Ele retirou troncos de árvore, enfeitou-os e, com a ajuda de duas cutias que cantavam e tocavam maracás, rezou, transformando os troncos em gente". Daí em diante, os diversos povos do alto Xingu criaram suas aldeias nas cercanias de Morená. Receberam do criador muitos conhecimentos e, através dos mama'e (espíritos), alguns deles se tornaram pajés, aptos a curar doenças.

Dentre os muitos mama'e existentes, ${ }^{2}$ alguns causam doenças em pessoas que transgridem dietas alimentares ou normas rituais, enquanto outros o fazem de modo aleatório, em especial quando se deparam com pessoas fragilizadas, como as que se acham em estágios liminares da existência (puberdade, viuvez, resguardo etc). A vítima tanto pode ficar doente, como ter sua alma capturada, o que pode levá-la a sofrer transtornos mentais ou mesmo ser levada à morte. Como já mencionamos, a morte deve ocorrer apenas nas idades avançadas e, se vier antes, busca-se a causa, pois não há morte indeterminada. Nas primeiras semanas após o nascimento, ela pode ser fruto do descuido dos pais que não observaram as regras alimentares; nos demais períodos da vida, pode ser causada pela ação intencional dos espíritos ou pelo feitiço (moã). ${ }^{3}$ Doenças causadas por espíritos podem ser identificadas e, na maioria dos casos, curadas por um pajé competente, exceto quando são fruto de uma transgressão ritual muito grave e cuja punição lançada pelo espírito é a morte do transgressor. Outra limitação do pajé é em relação ao feitiço feito com o propósito de matar e que não pode ser revertido. Nesses casos, a única função do pajé é, em meio a muitas operações, identificar o feiticeiro. Um pajé suficientemente poderoso pode matar

2 Etienne Samain identificou 32 mama'e e as respectivas doenças que causam, mas provavelmente há inúmeros outros, uma vez que pajés experientes afirmam que existem mais mama'e do que gente (1980, p.167-172).

${ }^{3}$ Os tipos de morte que não se enquadram nessa explicação são as mortes causadas por embates armados (frequentes no passado, mas hoje praticamente inexistentes), as brigas que resultem em óbito e a execução de feiticeiros pela comunidade. 
o feiticeiro por meio de operações mágicas realizadas com algum fragmento do corpo da vítima. Se isso não ocorrer, o feiticeiro pode vir a ser sacrificado por membros da comunidade. ${ }^{4} \mathrm{~A}$ crença na existência do feitiço é tão arraigada que, mesmo no caso de morte causada por acidente, advém a acusação de feitiçaria. Os Kamaiurá não aceitam a casualidade como fator que explique a cessação da vida. É imperiosa, em todas as circunstâncias, a determinação dos fatores que causaram a morte, sejam eles espíritos ou feiticeiros. Os espíritos atuam para punir transgressões, e os feiticeiros para eliminar adversários criados em meio a disputas políticas e intrigas familiares.

Ao primeiro sinal de que algo perturba o funcionamento regular do organismo, recorre-se aos remédios extraídos de plantas. A maioria deles foi distribuída à natureza por Mavutsinin, embora uns poucos tenham sido criados por entidades mitológicas. ${ }^{5}$ Várias plantas são conhecidas por praticamente todos os adultos e são eficazes para combater desarranjo intestinal, tosse, dor de ouvido e de dente, dores musculares, irritação da pele, ferimentos e outros pequenos desconfortos. Se o tratamento não fizer efeito, procura-se o raizeiro (y’apoajat), que detém conhecimento mais aprofundado do poder curativo das plantas, transmitido de pai para filho. Ele não só administra poções e adverte sobre os cuidados necessários para conduzir o tratamento, como testa novas drogas, fazendo a combinação de partes de uma mesma planta ou de várias delas, acumulando, assim, fórmulas específicas que são mantidas em segre-

${ }^{4}$ Para maior detalhamento da relação entre pajé e feiticeiro, consultar C. Junqueira (2005, p.147-161).

${ }^{5}$ É o caso de uma narrativa mitológica que relata a história de um homem que tinha uma cabacinha bem guardada e sempre alertava a filha para que não tocasse nela. Certo dia, a moça não resistiu à curiosidade e foi olhar seu conteúdo. Duas pequenas cobras saíram de lá e a mataram. O pai, ao constatar o desastre, fumou, em seguida fez com que as pequenas cobras fumassem e soltou-as, ordenando que matassem todos da aldeia. No decorrer da destruição que se seguiu, as cobras se tornavam sempre maiores. Os homens resolveram matá-las. Puseram mulheres e crianças no teto das casas e abriram duas grandes covas, uma perto da lagoa Mariwahet e outra na Iaununu. Atraíram as cobras que foram mortas a flechadas e enterradas nas covas. Nasceram ali dois tipos de remédio, um que apura a pontaria das pessoas e outro que as deixa forte na luta huka huka. do. Isso fica evidente quando a cura envolve escarificação e aplicação do sumo de raiz ralada, preparada na frente do paciente tão logo o sangue comece a fluir. O raizeiro, além de manipular a raiz longe do olhar dos outros, procura evitar que a planta seja identificada, guardando consigo as partes descartadas. O pagamento pelo serviço envolve colares ou valores equivalentes, de acordo com as relações de parentesco entre as partes ou as condições materiais da família do enfermo.

Em outras ocasiões, quando as providências domésticas não surtem efeito, a família do enfermo procura o agente de saúde indígena da própria aldeia, cujos serviços são gratuitos. As demandas mais frequentes envolvem casos de diarreia, gripe, escabiose, desnutrição e doenças venéreas. Doentes com enfermidades mais graves são encaminhados para o Posto Leonardo, que administra o Alto Xingu, onde ficam sob cuidados médicos, sendo eventualmente encaminhados ao hospital da cidade de Canarana (MT) ou de Brasília.

A solicitação dos serviços do pajé depende do diagnóstico realizado pelos próprios especialistas indígenas, da existência de pajé no círculo de parentes próximos do enfermo, ou da gravidade do caso. Como o tratamento deve ser pago, procura-se, nas primeiras etapas da doença, o auxílio da medicina convencional, gratuito, deixando a contratação do pajé como último recurso. A sequência de serviços do raizeiro, agente de saúde e pajé nem sempre ocorre nessa ordem. Doenças que logo de início deixam a pessoa muito debilitada, ou em que o paciente não quer deixar a aldeia ou ir para o hospital, por não gostar do acolhimento oferecido, ou ainda aqueles que depositam mais confiança na cura xamânica, são casos diretamente levados ao pajé.

Os pajés podem ser qualificados em duas categorias: os que foram iniciados por um mama'e (espírito), através do sonho (Junqueira, 2005), considerados os mais potentes, e os instruídos por outro pajé. Em tempos mais recuados, era comum o pajé cuidar da iniciação do próprio filho e, hoje em dia, pode-se pagar para ter acesso ao 
ensinamento. Além de identificar a procedência das doenças (mama'e ou feiticeiro), o pajé exerce muitos outros ofícios, como proferir rezas para fortalecer o corpo, afastar ameaças, propiciar bons acontecimentos, neutralizar o poder de feitiços, capturar almas raptadas por espíritos etc. Serviços à comunidade, como pajelanças nas pescarias coletivas, não são imediatamente pagos, mas retribuídos de modo difuso nas atenções e dádivas oferecidas na vida cotidiana. Trata-se de uma forma de reconhecimento que reafirma o poder. Todorov (1996) distingue duas modalidades de reconhecimento: de conformidade, que se refere ao cumprimento do dever das normas apropriadas ao exercício de uma função, e o de distinção, que atua como prêmio à excelência pessoal. Um reforça as relações comunitárias, e o outro, a competição. O pajé kamaiurá é merecedor de ambos: exerce um papel conservador importante, que reafirma a crença nos poderes espirituais, e, ao mesmo tempo, estimula uma competição velada entre seus pares, na busca de níveis crescentes do desempenho profissional.

A saúde é vista como qualidade inerente à vida. Genitores que seguem corretamente regras alimentares e procedimentos rituais geram filhos sadios, aptos a atravessarem as diversas etapas da existência humana até a velhice. Os males que podem atingir a pessoa não advêm do mau funcionamento do organismo, mas decorrem de forças externas que agridem o corpo. Eliminar a doença e restabelecer a saúde é a grande tarefa dos especialistas em ervas e pajés que, nos últimos sessenta anos, aproximadamente, passaram a contar com outro aliado, os profissionais da área médica. Embora fazendo uso de outras práticas, eles obtêm sucesso em boa parte das intervenções, mesmo que aplicando conceitos diferentes para embasar seu conhecimento sobre a etiologia das doenças. $O$ fato de o atendimento médico ser aberto a todos os moradores da aldeia e, além disso, ser gratuito, favorece sua aceitação. Questionamentos podem ocorrer se o paciente vier a morrer, o que geralmente é atribuído ao descaso ou à incompetência profissional. Por não operar com as noções de espírito e feitiço, responsáveis pela ocorrência da morte, a medicina convencional é representada como menos exigente do que o modelo indígena, pois é incapaz de apresentar a determinação legítima da causa externa que interrompeu a vida.

A crença em espíritos é a grande responsável pela atribuição de sentido ao mundo kamaiurá, sustentando as práticas que protegem o corpo, num campo em que descuidos e infrações acarretam doenças, e graves transgressões podem conduzir à morte. Na relação entre humanos e seres sobrenaturais, entretanto, existe o diálogo e, se a comunidade se submeter às regras ditadas pelos espíritos, pode contar com uma existência tranquila. O que não é o caso do feiticeiro, que escolhe sua vítima e sobre ela lança o ataque mortal. A pessoa alvejada é surpreendida pela força maligna, tornando-se, assim, uma presa desarmada sem condições de reagir. Diante disso, éfundamental que a causa dos desfechos fatais seja explicitada. Pois só assim será possível organizar a defesa da comunidade e, em momento posterior, eliminar o autor do crime.

O treinamento a que os agentes de saúde do Parque Indígena do Xingu se submeteram, sob a direção de profissionais da área médica da UNFESP, ${ }^{6}$ poderia ser visto como responsável pela introdução de inovações no cerne das concepções tradicionais sobre o corpo, a saúde e a doença. Na aldeia kamaiurá de Ipavu, entretanto, os jovens atendentes aceitam visivelmente a supremacia dos poderes xamânicos e dos seus fundamentos. $\mathrm{O}$ novo conhecimento que detêm coloca-os mais na área de atuação dos raizeiros, pois esboçam uma discreta comparação entre a eficácia dos medicamentos que administram e os remédios naturais.

Dentre os inúmeros cuidados dispensados ao corpo, selecionamos alguns, comumente usados nas diferentes etapas que pontuam a vida na comunidade. Em sua fase de crescimento, as crianças são estimuladas a aumentar sua participação na rotina dos afazeres. A partir dos 5 anos de idade, são, aos poucos, convocadas para realizar pequenos serviços, como dar e levar recados a vizinhos. À medida que crescem e adquirem mais ${ }^{6}$ Para uma visão analítica do programa de formação de agentes indígenas de saúde, ver: Mendonça (2005). 
desenvoltura, passam a carregar nenês dentro da casa, como forma de liberar a mãe. Por volta dos 10 anos, as meninas são iniciadas nos trabalhos domésticos e aprendem a ralar mandioca, acender o fogo e, as mais desenvolvidas, começam a fazer pequenos beijus. Pouco a pouco, carregam mais e mais peso, como feixes de lenha e cestos com pequena quantidade de mandioca. Se, quando pequenas, são muitas vezes choronas e birrentas, tornam-se, com o passar do tempo, mais cooperativas. É a partir dessa idade, antes da menarca, que elas podem vir a ser iniciadas sexualmente, “furadas”, como dizem. Não foi possível saber com exatidão a faixa etária dos parceiros, mas presume-se que sejam meninos um pouco mais velhos. Antes de entrar na reclusão pubertária (myngãu), a menina já realiza com destreza muitas das atividades executadas pela mulher adulta. Quando, finalmente, ocorre a primeira menstruação, ela é afastada do convívio direto com outras pessoas, isolando-se num canto da casa vedado por cortinas, onde pode permanecer de vários meses a até um ano. Nos primeiros dias de reclusão, ela permanece em jejum e só aos poucos começa a comer beiju bem fino, mingau (kauin), uma mistura de água e beiju dissolvido e carne de caça. A alimentação é servida pela mãe, e, pelo menos durante um mês, não lhe é permitido comer peixe. Tal restrição talvez tenha alguma ligação com o saber dos antigos sobre a origem da menstruação: Mavutsinin, quando fez a mulher, deixou dentro dela minúsculas piranhas que, a cada mês, beliscam suas entranhas, fazendo com que perca sangue. Ainda que atualmente essa explicação não faça parte do repertório kamaiurá, é possível que ela, de alguma forma, oriente a exclusão da carne de peixe durante a menstruação (maitsot). Enquanto seu corpo se fortalece, ela permanece isolada, sendo-lhe vedado qualquer contato com o sexo oposto. No pequeno recinto onde permanece, ela é banhada com a ajuda da mãe, que também a conduz à noite, com a cabeça coberta, até o mato próximo, onde vai evacuar.

A escarificação feita com o jajap (lê-se iaiap) é realizada por toda a vida, geralmente nos membros superiores e inferiores, com finalidades cura- tivas e para estimular a saúde de um modo geral. Depois da sangria, as feridas são lavadas com uma mistura de água e ervas (timokwit). Durante a reclusão, ela é feita para fortalecer o corpo, o que, junto com a dieta, visa a preparar o corpo da menina para a futura maternidade. Com bastante tempo livre durante esse período, a reclusa costuma ser treinada pela mãe em algumas artes femininas, como tecer esteiras e fiar algodão. Mas o objetivo principal da reclusão é ligado à saúde e ao amadurecimento do organismo, procurando-se também evitar que ela tenha relacionamento sexual. Ainda que a vigilância dos pais seja constante, há relatos antigos que registram a ocorrência de encontros secretos, com jovens rapazes se insinuando no recinto proibido.

A reclusão do menino (okipewat) se inicia quando ele apresenta sinais da puberdade. ${ }^{7}$ É mais longa e pode alcançar vários anos, intercalados de períodos de liberdade, principalmente se estiver sendo preparado para um futuro cargo de chefia. Da mesma forma que a menina, ele também se submete a um jejum inicial, que é seguido da ingestão do vomitório myritwi, responsável pela limpeza do corpo. Aos poucos, passa a beber kawin e comer beiju fino para, em seguida, passar a receber peixe cozido sem sal, pimenta ou gordura. Cerca de um mês depois, toma outro remédio de raiz para neutralizar o que foi ingerido nos primeiros dias, após o que começa, pouco a pouco, a comer peixe mais saboroso, desde que não-gorduroso. Depois de um último vomitório, ele experimenta peixe assado. O objetivo aqui é torná-lo forte para a luta huka-huka e resistente para o desempenho das funções masculinas, embora, durante o retiro, o pai possa transmitir-lhe técnicas de elaboração de artefatos. Relações sexuais prematuras podem diminuir seu vigor. ${ }^{8}$

A saída da reclusão significa uma ruptura com o universo infantil e a entrada na vida adulta. Tanto para meninas como meninos, ela marca o

${ }^{7}$ Vitti relaciona os sinais externos indicadores da puberdade masculina (2005, p.94).

${ }^{8}$ Para enfoques específicos sobre a reclusão masculina, consultar Pinto e Baruzzi (2005) e também Tavares (1994). 
início de atividade sexual mais regular e, para vários deles, é também a procura do parceiro para constituir família. A aproximação entre homem e mulher tem vários caminhos possíveis, e o mais comum é que a moça interessada pergunte se ele quer beiju ou kauin. Nessa fase preliminar, ela consulta a mãe, em busca de aprovação. Segundo relatam, o rapaz é mais direto e convida a mulher desejada a manterem relações sexuais. O casamento preferencial é entre primos cruzados ('atywahap), mas outros arranjos são possíveis e comuns. Não se recomenda o casamento antes de os parceiros terem tido relações sexuais e estarem seguros de sua escolha. Essa fase experimental não deve, entretanto, prolongar-se em demasia, principalmente se as relações se tornarem muito frequentes. Temese que a moça engravide e venha a dar à luz a um filho sem pai socialmente reconhecido.É da família da moça a iniciativa de entrar em contato com a do rapaz para a formalização da união, que consiste no simples ato de transferir sua rede para a casa dela, onde ele deverá prestar serviços aos sogros, como limpar a roça, trazer-lhes peixe, frutas etc.

O respeito (ipowe) é um preceito importante na cultura kamaiurá, por criar, em graus diferenciados, um distanciamento entre as pessoas, de modo a evitar que possíveis oposições se avolumem, convertendo-se em conflito aberto. As famílias procuram selar alianças, através do casamento, para se fortalecerem politicamente e ampliar o número de aliados tanto na própria aldeia como em outras. Se a união ocorrer entre primos cruzados, a relação entre as famílias tenderá a ser mais amigável, ao contrário do que acontece quando os parceiros estão fora desse circuito, em especial se pertencerem a grupos políticos opostos, o que torna a aliança um empreendimento de maior risco. Ao clima de suspeita de ambos os lados interpõese a formalização do comportamento, ditada pelo princípio do respeito, e a proibição de pronunciar, em qualquer circunstância, o nome do parente afim. A regra de evitação é mais estrita na relação entre genro e sogro (towajat): ${ }^{9}$ o genro não deve

${ }^{9}$ Segundo Seki. (2000, p. 465), o termo também significa inimigo. dirigir a palavra ao sogro e, não sendo possível evitar, é sua obrigação manter os olhos na direção do chão; não pode falar alto estando ele presente e deve ainda evitar cruzar com ele nos caminhos que percorrer. Transgressões fazem recair sobre a pessoa o sentimento de vergonha (ontsi).

Consumado o casamento, a expectativa é a de que a mulher engravide em pouco tempo, mesmo porque o nascimento de uma criança é o elo necessário à materialização da aliança, dado que a dissolução da união de casais sem filhos não é incomum. Como a infertilidade é um estigma que recai primeiramente sobre a mulher, a jovem esposa também tem pressa em engravidar, tornando público que não é infértil (memype'ym). Se, com o passar do tempo, isso não ocorrer, ela pede ao marido que lhe traga pitang, remédio extraído da raiz de um capim, para estimular a fecundidade, que deve ser tomado com água em jejum e também friccionado no ventre. Foi surpreendente a resposta dada por um informante já idoso e grande conhecedor de remédios, quando perguntamos o que seria possível fazer caso a gravidez não ocorresse dentro de um tempo razoável: "Quando a mulher só tem um homem, pode demorar a engravidar, mas, tendo dois, pega logo filho".

O marido tem igualmente recursos para auxiliá-lo na tarefa de engravidar a esposa, como o chá tatu-pewarakway, retirado de uma hera que nasce em troncos de árvores, e que pode também ser passado sobre o pênis para deixá-lo rijo. Outro remédio, do qual não foi possível obter o nome, é o sumo de uma frutinha semelhante à mangaba, usado também para friccionar o pênis. A perda ocasional da potência sexual (takwen-mano) não é considerada doença e, segundo os informantes, pode afligir qualquer homem em ocasiões as mais inesperadas. Na aldeia, fala-se, de modo um tanto brincalhão, que homens e mulheres que consomem regularmente o peixe wetsing assado, semelhante à bicuda, costumam ter muito vigor. Seu efeito é ainda mais promissor caso o homem extraia seu óleo e passe sobre o pênis.

Informantes mais velhos explicam que a fecundação ocorre quando o sêmen se mistura ao 
líquido que lubrifica a vagina. Quando a mulher sonha estar fazendo mohete, bebida feita com a água que lavou a mandioca brava, e este ferve, é sinal de que vai engravidar. Se o mohete seca na panela, ela não irá ter filho. Tão logo a mulher engravide (eweka), deve seguir uma dieta que inclui peixes, exceto alguns, como o peixe cachorra, que dará diarreia na criança, e a piranha vermelha, que fará com que ela nasça com os olhos vermelhos. Pode ainda comer algumas frutas, menos o abacaxi, nativo da região, que provoca aborto. Algumas mulheres deixam também de comer banana e mamão pelo mesmo motivo. A partir dos oito meses de gravidez, quando a criança já está formada, a dieta passa a incluir carne de caça. A dieta seguida corretamente assegura o desenvolvimento normal da criança e se estende ao marido, que deve ainda evitar alguns afazeres. De fato, não há um rol prévio de recomendações a serem seguidas, mas ilustrações de como certos trabalhos interferem na formação do feto. Num dos casos relatados, a criança nasceu com feição de jacaré, porque, durante a gravidez, o marido esculpiu um banco em forma de jacaré. Deduz-se que o homem deve se ater ao trabalho regular de provedor, em atividades rotineiras. Caso haja ameaça de aborto, quando, por exemplo, a mulher come piranha muito pequena, recomenda-se a ela adicionar à comida bastante pimenta do tipo bem pequeno (y'ky'yj).

O parto é realizado na própria casa, com a ajuda da mãe ou, na sua falta, da irmã ou de parente próxima. Se houver dificuldade no nascimento, chama-se uma mulher com muita experiência, uma espécie de parteira (pingamo’ahat), e, se o quadro se agravar, o pajé. Atualmente, com a presença do agente de saúde na aldeia, a parturiente pode vir a ser removida para o hospital da cidade de Canarana. O recém-nascido é examinado com cuidado, e seus membros são esticados para que fiquem retos. Sendo constatada má formação grave, cabeça muito grande, feição de animal etc, ele é sacrificado com veneno. Destino semelhante têm as crianças geradas por mãe solteira ou em relações fora do casamento, ou ainda os gêmeos; logo após o nascimento e sem que se cor- te o cordão umbilical, todos são enterrados junto com a placenta (wapawet ou aopap) no interior da casa. Nos últimos anos, têm sido registrado casos de crianças socialmente sem pai, criadas por avós ou mesmo pela própria mãe. Dizem os informantes que, de início, essas crianças eram discriminadas pela comunidade e, apenas mais recentemente, passaram a ser aceitas. Deve-se o gradual descumprimento dessa regra tradicional aos "brancos”, sempre contrários à prática, dizem os velhos kamaiurá, acrescentando que há casos dessa violação em quase todas as aldeias da região.

Há uma expectativa generalizada de que o primeiro filho seja homem e, caso a esposa gere meninas em gravidezes sucessivas, é comum que tome peke'yp wa'amykyt, droga indicada para estimular o nascimento de menino.

Após o nascimento da criança, a mãe toma o vomitório da raiz moãguê, para tirar o sangue que ainda esteja em seu corpo, ficando alguns dias em jejum. Em seguida, passa a tomar o mingau kauin e, durante o primeiro mês, só se alimenta de carne de caça e peixe pequeno. Tanto o peixe cachorra como peixe grande de qualquer espécie fazem com que a criança adoeça. Além das restrições alimentares, a mulher evita pegar lenha, ir à roça e fazer comida por cerca de quatro meses, sempre em função da saúde da criança. De modo similar, o marido permanece deitado durante cerca de quatro dias e, quando o umbigo do recém-nascido cai, toma uma infusão da raiz kawikita para vomitar. Passa, então, a receber a mesma alimentação da esposa, até a criança andar. Tanto a dieta alimentar como as atividades rotineiras do homem e da mulher só retornam ao padrão usual quando a criança completa três ou quatro anos. Se adicionarmos esse espaço de tempo ao da dieta que se inicia no momento em que a gravidez é registrada, um casal pode permanecer mais de quatro anos num regime especial de alimentação. Há, evidentemente, violações, atestadas pelas doenças que atingem crianças novas e que são publicamente apontadas por membros da comunidade. Uma forma de contornar o regime alimentar durante o período marcado por essas regras tornou-se possível com a 
introdução de alguns produtos industrializados, como o açúcar, que eventualmente pode substituir o mel de abelha (apontado como causador de feridas na cabeça da criança), o macarrão, arroz, feijão etc., mas de aquisição irregular e condicionada à disponibilidade de dinheiro e transporte..$^{10}$

Do mesmo modo que observam os cuidados tradicionais nos primeiros anos de vida, os adultos reconhecem, de modo unânime, a importância da vacinação regular realizada pela equipe médica. ${ }^{11} \mathrm{E}$ uma prática cultural que revela, ainda que indiretamente, a melhoria das condições de saúde da criança é a atribuição dos primeiros nomes pessoais. De acordo com o costume, os nomes passam dos avôs para os netos e, como não é permitido pronunciar o nome de parentes afins, a pessoa recebe dois nomes, um dado pela mãe e outro pelo pai. Em décadas passadas, a criança recebia seus primeiros nomes após seis ou oito meses de vida, ocasião em que os pais estavam mais seguros de que ela iria sobreviver. Com isso, evitavam a perda do nome, caso o recém-nascido viesse falecer, e asseguravam sua transmissão no futuro. Atualmente, é prática corrente a nominação bastante precoce: logo após o nascimento, crianças do sexo masculino são denominadas I'in, e as do sexo feminino Pia, ambos os nomes indicando o fato de o nenê não ter ainda nomes próprios, que serão recebidos um mês depois. ${ }^{12}$

Crianças novas costumam ser pintadas para ganhar força e vigor. Com a resina yhik e carvão (ywut) são feitos pequenos traços verticais no seu corpo com a ajuda de um palito, no padrão 'peixinho' (pykytsiin), ou com a ponta dos dedos

${ }^{10}$ Miriam Coelho de Souza observou, em 2003, o consumo em duas refeições diárias (manhã e tarde), durante seis dias, em 17 casas da aldeia de Ipavu, e registrou a presença de alimentos industrializados em 4 casas, num total de 12 refeições. Para a obtenção de dados mais completos, seria necessária uma observação ao longo dos diferentes meses do ano, durante o dia todo, uma vez que os Kamaiurá não têm refeições regulares e comem praticamente o dia todo.

${ }^{11}$ A Universidade Federal de São Paulo, via Escola Paulista de Medicina, atua no Parque Indígena do Xingu desde 1965, com um programa de saúde voltado aos povos da região. Na região do Alto Xingu, onde vivem os Kamaiurá, a UNIFESP deixou de atuar em 2004.

12 Agradecemos a Vaneska Taciana Vitti a informação sobre a atribuição de nomes nos dias atuais em Ipavu. são feitas bolinhas, no padrão denominado 'onça pequena' (jawari apinin).

Não se observa, na aldeia de Ipavu, criança engatinhando. A partir dos oitos meses de idade, ela é colocada de bruços sobre um pano no chão e quando começa a se mover muito, um adulto coloca-a de pé e, segurando-a pelos braços, faz com que ensaie alguns passos. Espera-se que, ao redor de um ano, ela comece a caminhar e, se isso não acontecer, o remédio akyky-arowai é passado em suas pernas durante quatro dias.

A maioria das crianças começa a falar com dois anos de idade. Para estimular a fala, costumase passar a língua do pássaro xexéu (o mesmo que japim) na língua da criança. Em média, a criança mama até dois anos e meio de idade, quando começa a desmamar espontaneamente. Mas há casos em que ela, embora recebendo outros alimentos, insiste em ter o leite materno. Nessas situações, ela é, vez por outra, consultada pela mãe se não gostaria de parar de mamar. Havendo concordância, a mãe passa em sua língua o y'jaraók, bichinho encontrado na areia da lagoa, fazendo cessar o desejo. A mulher pode eventualmente fazer uso do remédio warutsa para estimular a produção de leite.

Como a constituição da prole é uma tarefa que envolve várias restrições na vida cotidiana, o casal busca espaçar futuros nascimentos. Tenta-se interromper a gravidez indesejada com pira'in, remédio feito com a folha amassada e colocada em água morna, que deve ser tomado em jejum. Dizem que, em algumas horas, a mulher começa a perder sangue, expulsando o feto. Os contraceptivos mais comuns são o mangawaru'ijap e o kuranain, usados mensalmente. Mas caso a mulher não deseje mais ter filho toma o arapawa akawã depois da menstruação durante três dias. Nos meses seguintes, ela continua a tomar a mesma dose, e o sangue menstrual vai diminuindo até que cessa definitivamente. Não há remédio que possa reverter esse efeito.

A mulher está sempre às voltas com a questão da gravidez, num contexto cultural em que a relação sexual, inclusive fora do casamento, não é alvo de repressão, desde que não envolva evidentemente determinadas categorias de parentes. Ain- 
da que alimentem um ideal difuso de fidelidade, os Kamaiurá quebram a monotonia conjugal em aventuras amorosas, sendo mesmo possível afirmar que, para eles, o exercício da sexualidade contribui para a manutenção de um corpo saudável. Até mulheres que há muito passaram pela menopausa (maitsupik) vivem amores secretos, o mesmo acontecendo com homens velhos, que contornam eventuais dificuldades passando sobre o pênis os pelos (ta'akawat) do bambu infantil, que nascem perto do bulbo; dizem que a coceira estimula a ereção.

$$
* * *
$$

Na mitologia kamaiurá, Mavutsinin criou a vida humana, a base cultural da existência social e, juntamente com seus netos, Kwat e Yai, proveu o universo de importantes recursos naturais. Completadas as obras, deixaram as criaturas livres para enfrentar o devir, repetindo, assim, o desempenho de muitas entidades que povoam o imaginário mundial. Tornaram-se o que Eliade definiu como “deus otiosus" (1998, p. 46 seq): atuaram ativamente no princípio primordial, mas, em seguida, retiraram-se para suas moradas, ${ }^{13}$ onde se mantêm distanciados do destino humano. Há muitos mitos que relatam seus atos criadores e aventuras, mas sua influência é pequena no cotidiano da vida na aldeia. São citados para explicar a origem de vários fenômenos e características da natureza e, na cerimônia do Kwaryp, são rememorados os feitos de Mavutsinin quando da criação da humanidade, mas nenhum culto especifico lhe é dirigido. Os espíritos (mama'e) têm presença forte na aldeia, não só porque representam uma ameaça, mas também por oferecerem solução às necessidades correntes da vida. São eles que instruem os grandes pajés na identificação e cura das doenças, definem os cuidados fundamen-

${ }^{13}$ As divindades kamaiurá vivem em Morená, na confluência dos rios Ronuro, Culuene e Batovi. No dias atuais, é possível registrar a indicação do céu como sua morada, provavelmente em consequência do contato com o pensamento religioso de moradores da cidade. Mas, segundo informantes mais velhos e pajés, o céu pertence ao domínio dos pássaros, onde vivem numa grande aldeia e de onde avistam suas presas na terra. tais para a preservação da saúde, e, ao mesmo tempo, punem os transgressores com doença e mesmo morte. O sentido maior da sua presença deve-se ao fato de serem eles os grandes protetores da vida, atuando diretamente na gestação da mulher, no desenvolvimento do feto e na defesa da saúde da criança durante os primeiros anos de existência.

A religião kamaiurá protege a produção e a reprodução sociocultural do povo, sem a ideia de um sagrado transcendental; seus heróis e entidades possuem poder superior, mas pertencem ao mundo terrestre. Mavutsinin e seus familiares moram em Morená, a poucas horas da aldeia, e os mama'e se espalham pelas matas, águas e roças; vários deles vivem dentro das casas, junto aos objetos cerimoniais de quem são donos. Sua missão é ensinar a manter a saúde e preservar a vida cerimonial.

(Recebido para publicação em julho de 2009) (Aceito em setembro de 2009)

\section{REFERÊNCIAS}

AGOSTINHO, P. Kwarìp: mito e ritual no Alto Xingu. São Paulo: EPU/Ed. da Universidade de São Paulo, 1974.

ELIADE, M. Tratado de história das religiões. Trad. Fernando Tomaz e Natália Nunes. São Paulo: Martins Fontes, 1998.

EVANS-PRITCHARD, E.E. Bruxaria, oráculos e magia entre os Azande. Trad. Eduardo Batalha Viveiros de Castro. Rio de Janeiro: Zahar Editores, 1978.

GALVÃO, E. (Org.) Encontro de sociedades: índios e brancos no Brasil. Rio de Janeiro: Paz e Terra, 1979.

JUNQUEIRA, C. Pajés e feiticeiros. In: BARUZZI, R.G. (Org.) Parque indígena do Xingu. Saúde, cultura e história. São Paulo: Terra Virgem Editora, 2005. p.147161.

Os índios do Ipavu: um estudo sobre a vida do grupo Kamaiurá. 2.ed. São Paulo: Ática, 1978.

MATURANA, H. Emoções e linguagem na educação e na política. Trad. José Fernando Campos Fortes. Belo Horizonte: UFMG, [1998] 2005. 4ª Reimpressão.

MENDONÇA, S. B. O Agente indígena de saúde no Parque Indígena do Xingu. In: BARUZZI, Roberto G. JUNQUEIRA, Carmen (Org.) Parque Indígena do Xingu: saúde, cultura e história. São Paulo: Terra Virgem Editora, 2005. p.227-244

OBERG, K. Indian tribes of Northern Mato Grosso, Brazil. Washington,DC: Smithsonian institution; Institute of Social Anthropology. 1953. (Publication, n.15) 
PINTO, N.R.S.; BARUZZI, R.G. Reclusão pubertária masculina em índios do Alto Xingu, Brasil Central. In: BARUZZI, Roberto G.; JUNQUEIRA, Carmen (Org.) Parque Indígena do Xingu: saúde, cultura e história. São Paulo: Terra Virgem, 2005. p.175-187.

SAMAIN, E. De um caminho para outro. Mitos e aspectos da realidade social nos índios Kamayrá (Alto Xingu). 1980. Dissertação (Mestrado em Antropologia) - Programa de Pós-Graduação em Ciências Sociais da Universidade Federal do Rio de Janeiro, 1980.

SEKI, L. Gramática do Kamaiurá: língua Tupi-Guarani do Alto Xingu. Campinas: Ed. Unicamp; São Paulo, SP: Imprensa Oficial, 2000.

TAVARES, S.C. A reclusão pubertária no Kamayurá de Ipawu. Um enfoque biocultural. 1994. Dissertação (Mestrado em Educação Física) - Programa de Pós-Graduação da Faculdade de Educação Física da Universidade Estadual de Campinas, 1994.
TODOROV, T. A vida em comum. Ensaio de antropologia geral. Trad. Denise Bottman e Eleonora Bottman.Campinas,SP: Papirus, 1996.

VILLAS BÔAS, O. A arte do pajés: impressões sobre o universo espiritual do índio xinguano. São Paulo: Globo, 2000.

VITTI, Vaneska Taciana. Jovens kamaiurá no século XXI. 2005. Dissertação (Mestrado em Antropologia) - Programa de Pós-Graduacão em Ciências Sociais da Pontifícia Universidade Católica de São Paulo, 2005. 


\section{THE KAMAIURÁ WISDOM ABOUT BODY HEALTH}

\section{Carmen Junqueira \\ Heloisa Pagliaro}

Kamaiurá are a Tupi language people that, together with people of the linguistic families Aruak, Karib, Tupi and of the isolated language Trumai, inhabits High Xingu (MT). The cultural homogeneity among those peoples is evidenced in multiple aspects, such as shape and disposition of the villages, type of housing, alimentary habits pubertary seclusion, paintings and corporal decorations, use of uluri by women, parties and ceremonies, such as Kwaryp. This common cultural pattern results of the long occupation of a same geographical area and of the frequency of interethnic marriages. The present work shows how the knowledge about body health is built from elements that compose the Kamaiurá world vision, in which observation, experimentation and mythology unite. The paper describes the cares given to the body and the cultural and spiritual rules regarding the different stages of the vital cycle.

KEYwords: Kamaiurá, indigenous health, reproductive health of indigenous people.

\section{LE SAVOIR KAMAIURÁ A PROPOS DE LA SANTE DU CORPS \\ Carmen Junqueira \\ Heloisa Pagliaro}

Les Kamaiurá sont un peuple de langue Tupi qui, avec les peuples des familles linguistiques Aruak, Karib, Tupi et de la langue isolée Trumai, habitent le Alto Xingu (MT). L'homogénéité culturelle de ces peuples est mise en évidence sous divers aspects, tels que la forme et la disposition des villages, le type d'habitation, les habitudes alimentaires, la réclusion pubertaire, les peintures et les ornements corporels, l'utilisation de l'uluri par les femmes, les fêtes et les cérémonies comme le Kwaryp. Ces normes culturelles communes résultent d'une longue occupation d'un même espace géographique et de la fréquence des mariages interethniques. Cette étude montre comment le savoir concernant la santé du corps est construit à partir d'éléments qui composent la manière de voir du monde Kamaiurá où l'observation, les expériences et la mythologie se mélangent. On y décrit les soins donnés au corps et les règles culturelles et spirituelles relatives aux différentes étapes du cycle vital.

Mots-CLÉs: Kamaiurá, santé indigène, santé de la reproduction des peuples indigènes.

Carmen Junqueira - Etnóloga, doutora em Antropologia pela UNICAMP e professora titular e emérita do Departamento de Antropologia da Faculdade de Ciências Sociais da Pontifícia Universidade Católica de São Paulo. Estuda povos indígenas dos estados de São Paulo, Acre, Rondônia e Mato Grosso. Pesquisa os Kamaiurá (MT) desde 1965. Além de inúmeros artigos em periódicos nacionais e estrangeiros, publicou diversos livros, como "Os Índios do Ipavu" (1979), "Sexo e Desigualdade entre os Kamaiurá e os Cinta Larga” (2002) e "Parque Indígena do Xingu. Saúde, Cultura e História” (2005).

Heloísa Pagliaro - Cientista social, mestre em Demografia pelo Instituto de Demografia da Universidade de Paris I e doutora em Saúde Pública pela Universidade de São Paulo. É lotada no Centro de Recursos Humanos da UFBA e está em exercício no Departamento de Medicina Preventiva da Universidade Federal de São Paulo, onde desenvolve pesquisa demográfica junto a povos indígenas, no âmbito do Programa de Saúde dos Povos do Parque Indígena do Xingu - Projeto Xingu. É Bolsista de Produtividade de Pesquisa II do CNPq e integra o GT Demografia dos Povos Indígenas da Associação Brasileira de Estudos Populacionais. Além de artigos em periódicos nacionais e internacionais e capítulos em livros, publicou "Demografia dos Povos Indígenas no Brasil” (2005). 